\title{
Oscillometrically Measured Aortic Pulse Wave Velocity Reveals Asymptomatic Carotid Atherosclerosis in a Middle-Aged, Apparently Healthy Population
}

\author{
Renáta Marietta Böcskei, ${ }^{1,2}$ Béla Benczúr, ${ }^{3}$ Veronika Müller, ${ }^{2}$ András Bikov (D), \\ Andrea Székely, ${ }^{4}$ Thomas Kahan, ${ }^{5}$ Zsófia Lenkey, ${ }^{1}$ Róbert Husznai, ${ }^{1}$ Attila Cziráki $\mathbb{D}^{1}{ }^{1}$ \\ and Miklós Illyés ${ }^{1}$ \\ ${ }^{1}$ Heart Institute, Medical School, University of Pécs, Pécs, Hungary \\ ${ }^{2}$ Department of Pulmonology, Semmelweis University, Budapest, Hungary \\ ${ }^{3} 1$ st Department of Internal Medicine, Balassa Janos County Hospital, Szekszárd, Hungary \\ ${ }^{4}$ Department of Anesthesiology and Intensive Care of Semmelweis University, Budapest, Hungary \\ ${ }^{5}$ Department of Clinical Sciences, Danderyd Hospital, Division of Cardiovascular Medicine, Karolinska Institutet, \\ Stockholm, Sweden \\ Correspondence should be addressed to Attila Cziráki; acziraki.pecs@gmail.com
}

Received 2 April 2019; Revised 24 July 2019; Accepted 13 September 2019; Published 18 January 2020

Academic Editor: Yoshinari Uehara

Copyright (C) 2020 Renáta Marietta Böcskei et al. This is an open access article distributed under the Creative Commons Attribution License, which permits unrestricted use, distribution, and reproduction in any medium, provided the original work is properly cited.

\begin{abstract}
Background. Asymptomatic atherosclerosis is a common entity even at young age. Studies have suggested a strong relationship between increased arterial stiffness and asymptomatic carotid atherosclerosis (ACA) in general population, particularly in those with high cardiovascular risk, but no data exist from a younger population free from recognized cardiovascular disease. $H y$ pothesis. We hypothesized there is an association between ACA and aortic pulse wave velocity (PWVao) in middle-aged, apparently healthy, normotensive population to reveal increased cardiovascular risk. Methods. We examined the relationship between ACA and PWVao in 236 apparently healthy, asymptomatic, normotensive, middle-aged subjects (age $47 \pm 8$ years; $52 \%$ women). PWVao was measured with the oscillometric method (Arteriograph). ACA was assessed by carotid artery ultrasonography. Results. ACA was present in 51 subjects. Subjects with ACA were older $(p<0.009)$, more likely to be smokers $(p<0.001)$, and had higher systolic blood pressure (SBP, $128 \pm 9$ vs. $125 \pm 10 \mathrm{mmHg}, p=0.048)$ and PWVao (9.3 \pm 1.6 vs. $7.9 \pm 1.3 \mathrm{~m} / \mathrm{s}, p<0.001$ ) than subjects without ACA. In a stepwise logistic regression analysis, only PWVao (odds ratio: 1.88 , $p<0.001$ ), smoking habit (odds ratio 3.79, $p=0.003$ ), systolic blood pressure (odds ratio 1.05, $p=0.046$ ), and diastolic blood pressure (odds ratio: $0.94, p=0.038$ ) were independently associated with ACA. PWVao $>8.3 \mathrm{~m} / \mathrm{s}$ identified ACA with a $71 \%$ sensitivity, $65 \%$ specificity, $36 \%$ positive and $89 \%$ negative predictive value, 2.04 relative risk, and 4.54 odds ratio, respectively. Conclusions. PWVao measured by the Arteriograph proved to be an independent marker of ACA. Our study may reveal high CV risk, detected as increased PWVao, which according to our study is related in a very high probability to asymptomatic carotid atherosclerosis in apparently healthy, young, and middle-aged subjects.
\end{abstract}

\section{Introduction}

Identifying asymptomatic atherosclerosis in apparently healthy, middle-aged patients has high clinical impact to detect increased cardiovascular risk [1,2]. The Systematic Coronary Risk Estimation (SCORE) has its limitations regarding the prediction of future cardiovascular $(\mathrm{CV})$ events as more than $80 \%$ of the events occur in patients of low- and middle-income countries, where the prognostic power of SCORE has not investigated and validated [3]. Furthermore, young and middle-aged population is more prone to nonfatal $\mathrm{CV}$ events than fatal cardiac diseases so 
that the SCORE can hardly be used as an accurate tool for predicting overall $\mathrm{CV}$ risk as it determines only $\mathrm{CV}$ mortality. Furthermore, the SCORE cannot be used under 40 years of age although the prevalence of aortic atherosclerosis was found to be $62.5 \%$ and $61.5 \%$ in men and women aged 30-34 years [4].

The gold standard diagnostic tool to reveal an asymptomatic carotid atherosclerosis (ACA) is the ultrasound examination of the extracranial part of both carotid arteries. Many studies emphasize the added value of measuring and characterizing carotid plaques beside intima-media thickness (IMT) when predicting CV risk $[5,6]$. Despite the hardly questionable evidence of an early onset atherosclerosis gained by the PDAY Study [4], moreover the known low performance of SCORE to predict CV events in this population, the 2016 European Society of Cardiology Guidelines on cardiovascular disease prevention in clinical practice concludes that "routine screening with imaging modalities to predict future $\mathrm{CV}$ events is generally not recommended in clinical practice and should only be used as a risk modifier in individuals with calculated $\mathrm{CV}$ risks based on the major conventional risk factors around the decisional thresholds" [7]. Consequently, an easy-to-perform, low-cost, validated method that can identify apparently healthy middle-aged patients with high cardiovascular risk by detecting asymptomatic atherosclerosis would have great clinical importance.

Aortic pulse wave velocity (PWVao) is a widely accepted marker of high CV risk, and it has an additive value in risk assessment beyond traditional risk factors [8, 9]. Former studies, demonstrating a strong relationship between PWVao and ACA [10-12], have made PWVao a promising method to reveal high risk subjects with ACA [13]. However, the generally accepted and most frequently used applanation tonometric and piezoelectric methods to measure aortic PWV may not really be suitable for the clinical practice because of their time-consuming, sophisticated manner and they also require trained personnel.

According to our knowledge, no publication is available which investigated the relationship between ACA detected by ultrasound and regional (aortic arch to bifurcation) aortic stiffness, measured as aortic PWV in middle-aged, apparently healthy, normotensive subjects. However, it has also been proven that early detection of a target organ damage such as ACA representing high $\mathrm{CV}$ risk can lead to earlier and more effective therapeutic strategies $[14,15]$.

Therefore, the aim of our study was to examine the association between ACA and PWVao with a clinically easily implementable, simple and fast oscillometric method in middle-aged, apparently healthy, normotensive population to reveal high $\mathrm{CV}$ risk.

\section{Methods}

2.1. Study Population. In this observational cross-sectional study, we measured a relatively big cohort, 781 subjects (aged $57 \pm 12$ ), who attended our daycare center of Heart Institute, Medical School, University of Pécs, Hungary, by their own initiative for a cardiovascular checkup. Figure 1 displays the enrollment of participants into the study.
In this study, apparently healthy, young, and middle-aged subjects were included, provided they were without any complaints or case history for coronary heart disease or stroke. Exclusion criteria of this cross-sectional study were coronary heart disease, hypertension, atrial fibrillation, tachycardia (heart rate above 90beats/min), stroke, peripheral arterial disease, chronic kidney disease, diabetes mellitus, and statin use. Those patients who were previously diagnosed with coronary heart disease (e.g., positive case history, or who had experienced for angina pectoris or who had positive coronary angiography/positive coronary CT scan) were excluded. Hypertension was defined as systolic blood pressure $\geq 140 \mathrm{mmHg}$, diastolic blood pressure $\geq 90 \mathrm{mmHg}$, or current use of antihypertensive medication. Diabetes mellitus was defined as a current use of oral antidiabetic drugs, insulin, or a self-reported diagnosis. Chronic kidney disease was excluded by anamnestic data and according to laboratory parameters (GFR lower than $60 \mathrm{ml} / \mathrm{min} / 1.73 \mathrm{~m}^{2}$ ). Current smoking status was self-reported. Thus, 236 (age $47 \pm 8$ years; 52\% women) apparently healthy, normotensive subjects remained for statistical analyses. Baseline characteristics, including patient history, physical examination, and serum total cholesterol values were obtained by standard procedures. The study was been approved by the local Institutional Ethics Committee of the University of Pécs, Pécs, Hungary (PTE KK RIKEB - 5111/2013), and all participants gave their oral and written informed consent.

2.2. Carotid Artery Ultrasound Examination. All carotid artery ultrasound examinations were performed by one single examiner using a HP Sonos 2000 device with a $7.5 \mathrm{MHz}$ linear probe (Hewlett Packard Ltd., Andover, Massachusetts, USA) on the same day and within 1 hour of the measurement of arterial stiffness. The whole extracranial carotid artery system was examined bilaterally, and we followed the American Society of Echocardiography (ASE) guidelines regarding standard screening methods of carotid plaques [5]. Near and far walls of all arterial segments (common carotid artery, carotid bifurcation, and the origins (first $2 \mathrm{~cm}$ ) of the internal carotid arteries and external carotid arteries) were scanned longitudinally and transversally to assess the presence of asymptomatic carotid artery atherosclerosis. Asymptomatic carotid atherosclerosis (ACA) was defined according to the European Mannheim consensus [16]. The presence of a plaque in the carotid artery was defined as a focal structure encroaching into the arterial lumen of at least $0.5 \mathrm{~mm}$ or $50 \%$ of the surrounding IMT value or demonstrates a thickness $>1.5 \mathrm{~mm}$ as measured from the media-adventitia interface to the intima lumen interface.

2.3. Aortic Stiffness. The simultaneous measurements of PWVao and blood pressure were performed in the supine position after 10 minutes of rest by an invasively validated oscillometric, occlusive, noninvasive technique (Arteriograph, TensioMed Ltd., Budapest, Hungary). This method allows very simple, fast, and user-independent measurement of aortic PWV using only a single upper arm cuff. The variability and reproducibility of the Arteriograph measured 


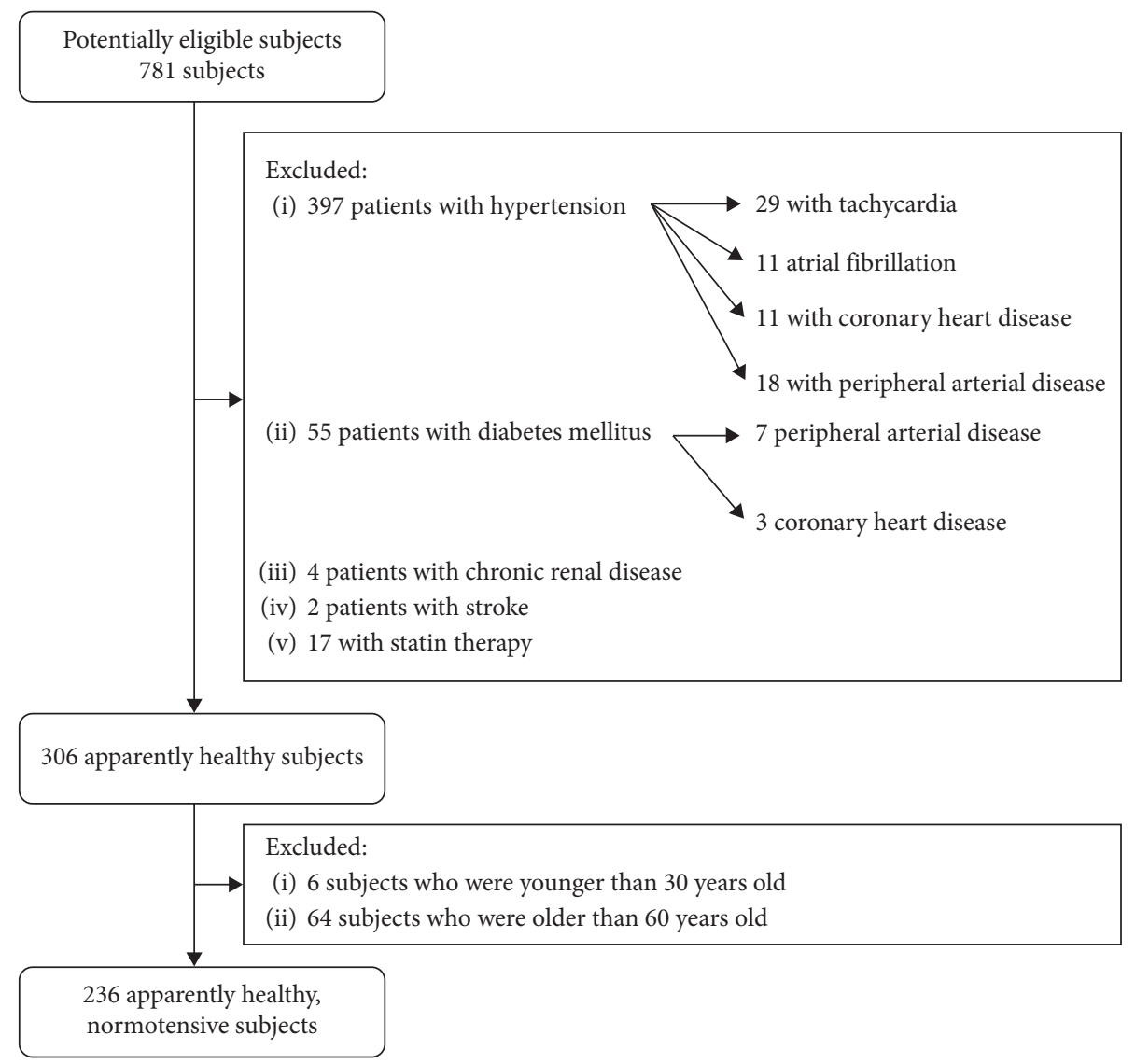

FIgURE 1: Flow chart of the number and selection of individuals in the study population.

aortic PWV reported to be superior compared to applanation tonometric and piezoelectric methods [17]. Details of the method and its invasive validation have been published previously [18]. In brief, the device first measures the actual brachial blood pressure oscillometrically with a clinically validated algorithm [19] and then inflates the cuff to suprasystolic pressure, completely occluding the brachial artery. During this condition, pure pressure signals can be collected by the cuff with pronounced and easily detectable direct and reflected systolic wave peaks. The time difference between the early and late systolic peaks is equal to the time of the aortic pulse wave traveling down to the aortic bifurcation and back towards the heart. From this, the aortic root-bifurcation transit time can be calculated, and by measuring the straight distance between the suprasternal notch and pubic bone (an acceptable estimate of the aortic length), the PWVao can be calculated.

As an estimate for the measurement errors for the repeat measurements of PWVao with Arteriograph, the variance within one session was $0.18 \mathrm{~m}^{2} / \mathrm{s}$ [2] and between two sessions was $1.18 \mathrm{~m}^{2} / \mathrm{s}^{2}$ [17].

2.4. Statistical Analyses. Data are reported as mean values \pm SD. Group means of continuous variables were compared with independent samples Student's t-test, whereas groups of categorical variables were analyzed with the $\chi^{2}$ test. Stepwise logistic regression was used to define predictor variables for the binary outcome of the presence of ACA. Receiver operating characteristics (ROC) analysis was performed to assess threshold values for PWVao relative to ACA. A probability $(p)<0.05$ was considered to be significant. Data were analyzed using SPSS 16.0 statistical package (SPSS Inc., Chicago, Illinois, USA).

The sample size was estimated to detect differences in PWVao between patients with and without ACA with an effect size of 0.38 and power of 0.80 . The effect size was based on the distribution and the variability of PWVao data [17].

\section{Results}

236 asymptomatic normotensive subjects (age $47 \pm 8$ years; $52 \%$ women) comprised the study group. The participants' characteristics are presented in Table 1. ACA was present in 51 subjects $(22 \%)$.

There were no differences between subjects with and without ACA in gender, BMI, total cholesterol, or HR. However, age, smoking, SBP, and PWVao were higher in the ACA group compared to ACA negative subjects $(50 \pm 8$ vs. $47 \pm 8$ years, $p=0.009 ; \quad 29 \% \quad$ vs. $8.3 \%, \quad p<0.001$; $128 \pm 9 \mathrm{mmHg}$ vs. $125 \pm 10 \mathrm{mmHg}, p=0.048 ; 9 \pm 2 \mathrm{~m} / \mathrm{s}$ vs. $8 \pm 1 \mathrm{~m} / \mathrm{s}, p<0.001$, respectively). A stepwise logistic regression including age, gender, BMI, smoking habit, SBP and DBP, HR, and PWVao was used to reveal parameters independently related to ACA. PWVao, smoking habits, and SBP and DBP were independently associated with ACA 
TABle 1: Descriptive data of the study population according to carotid artery atherosclerosis.

\begin{tabular}{|c|c|c|c|c|c|}
\hline & \multirow{2}{*}{$N$} & \multirow{2}{*}{ All } & \multicolumn{2}{|c|}{ Carotid atherosclerosis } & \multirow{2}{*}{$p$} \\
\hline & & & Negative & Positive & \\
\hline$N$ & & 236 & 185 & 51 & \\
\hline Age (years) & 236 & $47 \pm 8$ & $47 \pm 8$ & $50 \pm 8$ & 0.009 \\
\hline Weight (kg) & 236 & $76.0 \pm 16.0$ & $75.5 \pm 15.7$ & $77.9 \pm 17.1$ & 0.344 \\
\hline Height $(\mathrm{cm})$ & 236 & $172 \pm 10$ & $171 \pm 9$ & $173 \pm 11$ & 0.295 \\
\hline $\operatorname{BMI}\left(\mathrm{kg} / \mathrm{m}^{2}\right)$ & 236 & $25.7 \pm 4.1$ & $25.6 \pm 4.1$ & $25.8 \pm 3.9$ & 0.735 \\
\hline Serum total cholesterol $(\mathrm{mmol} / \mathrm{l})$ & 134 & $5.6 \pm 1.3$ & $5.6 \pm 1.3$ & $5.9 \pm 1.5$ & 0.240 \\
\hline SBP $(\mathrm{mmHg})$ & 236 & $125 \pm 10$ & $125 \pm 10$ & $128 \pm 9$ & 0.048 \\
\hline DBP (mmHg) & 236 & $75 \pm 8$ & $75 \pm 8$ & $76 \pm 7$ & 0.671 \\
\hline MAP (mmHg) & 236 & $92 \pm 7$ & $92 \pm 8$ & $93 \pm 7$ & 0.228 \\
\hline $\mathrm{PP}(\mathrm{mmHg})$ & 236 & $50 \pm 8$ & $50 \pm 8$ & $52 \pm 8$ & 0.049 \\
\hline HR (beats per min) & 236 & $70 \pm 9$ & $70 \pm 9$ & $71 \pm 10$ & 0.380 \\
\hline PWVao $(\mathrm{m} / \mathrm{s})$ & 236 & $8.2 \pm 1.5$ & $7.9 \pm 1.3$ & $9.3 \pm 1.6$ & $<0.001$ \\
\hline Female/male & 236 & $122 / 114$ & $98 / 87$ & $24 / 27$ & 0.45 \\
\hline Smoker/nonsmoker & 236 & $30 / 206$ & $\begin{array}{c}15 / 170 \\
8.3 \%\end{array}$ & $\begin{array}{l}15 / 36 \\
29 \%\end{array}$ & $<0.001$ \\
\hline
\end{tabular}

BMI, body mass index; SBP, systolic blood pressure; DBP, diastolic blood pressure; MAP, mean arterial pressure; PP, pulse pressure; HR, heart rate; PWVao, aortic pulse wave velocity. Values are presented as mean \pm standard deviation.

TABLE 2: Independent markers of asymptomatic carotid artery atherosclerosis by stepwise logistic regression analysis.

\begin{tabular}{lcc}
\hline & Odds ratio and 95\% confidence limits for 1 unit & $p$ \\
change & $<0.001$ \\
PWVao (m/s) & $1.88[1.44 ; 2.50]$ & 0.003 \\
Smoker (yes/no) & $3.79[1.56 ; 9.22]$ & 0.046 \\
SBP (mmHg) & $1.05[1.001 ; 1.10]$ & 0.038 \\
DBP (mmHg) & $0.94[0.89 ; 0.99]$ & 0.96 \\
\hline
\end{tabular}

A stepwise logistic regression including age, gender, body mass index, smoking habits, systolic and diastolic blood pressure, heart rate, and PWVao showed aortic PWV, smoking, and systolic and diastolic blood pressure to be significant independent markers. PWVao, aortic pulse wave velocity; SBP, systolic blood pressure; DBP, diastolic blood pressure.

(Table 2). Age was not an independent marker of ACA. Based on the calculated odds ratio (1.88) and the $\mathrm{SD}(1.6 \mathrm{~m} / \mathrm{s})$ of PWVao, 1 SD increase of PWVao almost duplicated (98\%) the risk of ACA, supposing that other parameters remained unchanged.

A receiver operating characteristic (ROC) curve analysis was performed to determine the optimal threshold value of PWVao for detecting ACA. This value proved to be $8.3 \mathrm{~m} / \mathrm{s}$ (Figure 2).

The area under the curve was 0.751 , and the optimal PWVao threshold proved to be $8.3 \mathrm{~m} / \mathrm{s}$, with a sensitivity of 0.71 and a specificity of 0.65 (see Table 3 for details).

Using this cutoff value of PWVao, the sensitivity, specificity, positive and negative predictive values, relative risk, and odds ratio for ACA were 0.71, 0.65, 0.36, 0.89, 2.04, and 4.54 , respectively (Table 3 ).

The prevalence of asymptomatic carotid atherosclerosis is $22 \%$.

\section{Discussion}

The most important finding of our study was that oscillometrically, the Arteriograph measured PWVao proved to be an independent marker of ACA. It is important to

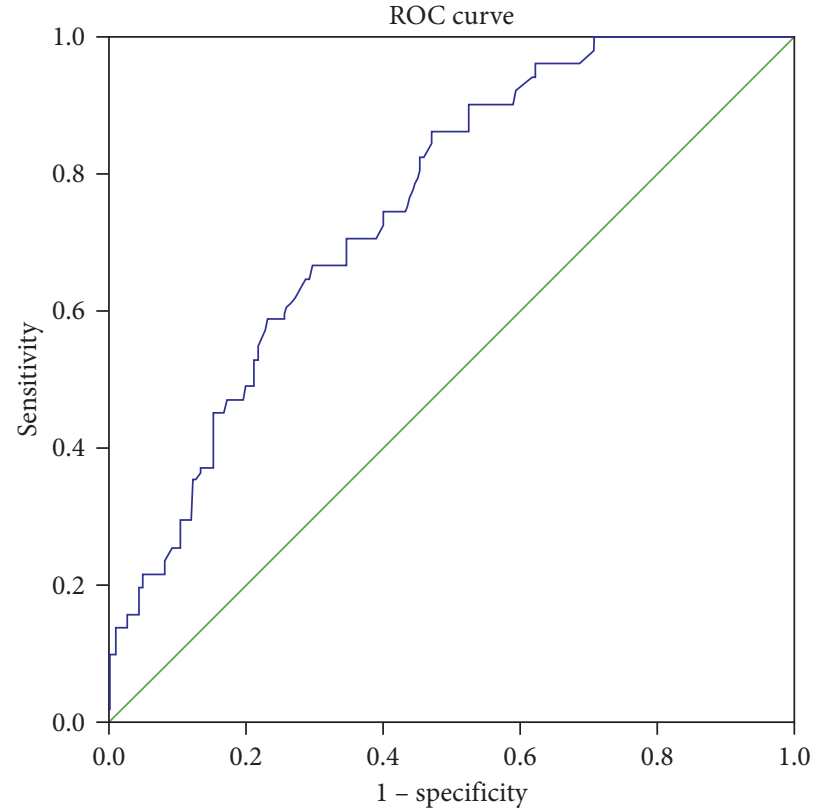

FIgURE 2: Receiver operating characteristic curve determining asymptomatic carotid atherosclerosis by measuring aortic pulse wave analysis. 
TABLE 3: Sensitivity and specificity of using $8.3 \mathrm{~m} / \mathrm{s}$ as a cutoff value of aortic pulse wave velocity to reveal asymptomatic carotid atherosclerosis.

\begin{tabular}{lcc}
\hline & Value & $95 \%$ CI \\
\hline Sensitivity & 0.71 & $0.56-0.83$ \\
Specificity & 0.65 & $0.58-0.72$ \\
Positive predictive value & 0.36 & $0.27-0.46$ \\
Negative predictive value & 0.89 & $0.82-0.94$ \\
Relative risk & 2.04 & $1.56-2.66$ \\
Odds ratio & 4.54 & $2.31-8.91$ \\
\hline
\end{tabular}

CI indicates confidence interval.

emphasize that age did not turn to be an independent factor of asymptomatic carotid atherosclerosis in this population. Although subjects with ACA were older compared to those without ACA, the difference (3.3 years) was modest. More importantly, the prevalence of ACA was $22 \%$ which is surprisingly high in this relatively young and apparently healthy population.

However, the other authors also found similar ACA prevalence in almost identical population. Roman et al. [20] investigated the relationship between asymptomatic carotid atherosclerosis and left ventricular hypertrophy in a large cohort of untreated hypertensive and normotensive patients free from overt cardiovascular or cerebrovascular disease. Sixteen percent of the 277 normotensive patients had ACA based on the carotid ultrasound examination. The mean age of the population was similar to ours ( $49 \pm 12$ years). In their study, age, SBP, and PP proved to be significantly higher in normotensive patients with asymptomatic carotid atherosclerosis.

In our study, the age independency of PWVao to reveal ACA maybe of paramount importance since most of cardiovascular risk scores are age-driven. Consequently, many older people are considered to have high CV risk despite of their normal cardiovascular status. However, subjects with low or moderate risk could be missed from the cardiovascular screening program because of their lower risk score driven by their younger age. Consequently, therapeutic intervention cannot be performed in time and fatal consequences may occur. However, several results confirmed that atherosclerotic process begins even at a very young age $[4,21]$. Furthermore, it has to be emphasized that almost $60 \%$ of cardiovascular and cerebrovascular events occur among low-risk patients involving three-quarters of the population [22], where traditional risk factors do not identify the majority of patients who will develop cardiovascular disease in the next 10 years [23-25]. Consequently, measuring PWVao oscillometrically in an apparently healthy, middle-aged population to find individuals with asymptomatic atherosclerosis, who will take advantage from early intervention and aggressive treatment, may have great clinical importance.

We found $71 \%$ sensitivity for ACA by using the PWVao threshold value of $8.3 \mathrm{~m} / \mathrm{s}$ based on the ROC curve in this middle-aged, apparently healthy, normotensive population, in which sensitivity seems to be acceptable. Our opinion could be supported by the fact that the sensitivity of the commonly used exercise ECG as a routine procedure to diagnose the presence of coronary artery disease in only 45-50\% according to the 2013 ESC guidelines on the management of stable coronary artery disease [26]. Consequently, based on the fast, user-independent, easy application of the Arteriograph, this higher sensitivity seems to be acceptable for screening of asymptomatic atherosclerosis assuming that atherosclerosis is the systemic disease of the intimal layer of middle and large arteries potentially having long latent subclinical phase and can affect the carotid arteries as well as the coronary arteries [27]. The observed relatively low positive predictive value of $36 \%$ may result from the low prevalence of ACA positive cases in this study population. However, the high negative predictive value means that the majority of patients with PWVao lower than $8.3 \mathrm{~m} / \mathrm{s}$ are unaffected from ACA. The relative risk and the odds ratio of the test proved to be 2.04 and 4.54, respectively, referring that the PWVao measurement seems to be a suitable screening tool for ACA.

The $8.3 \mathrm{~m} / \mathrm{s}$ PWVao cutoff value for ACA in our study with middle-aged hypertensive patients was lower than it was recommended $(10 \mathrm{~m} / \mathrm{s})$ by the ESC/ESH guidelines for the management of arterial hypertension as a marker of aortic stiffness and underlying arteriosclerosis [28, 29]. However, it must be emphasized that this higher cutoff value suggested by the guidelines does not refer only to ACA.

The relatively low age of our study population may point out that asymptomatic carotid atherosclerosis can be present even when PWVao is moderately elevated. Consequently, the $10 \mathrm{~m} / \mathrm{s}$ general cutoff value may not be used for all the patients of different ages to estimate cardiovascular outcomes.

Our results were obtained by applying an ease-of-use, oscillometric method for measuring PWVao, which simplifies the PWVao measurement in the routine clinical work. This might be particularly useful for improvement of cardiovascular risk factor assessment in the primary care setting, where simplicity, user independency, and swiftness are mandatory requirements. It has to be emphasized that according to the 2016 European guidelines on cardiovascular disease prevention in clinical practice, the atherosclerotic plaque detection by carotid ultrasound as a risk modifier in $\mathrm{CV}$ risk assessment while IMT measurement is not recommended [26]. It is also worth mentioning that carotid ultrasound examination is hardly available in the primary care setting [7]. Despite the conclusion of the previously mentioned guideline [26], the SHAPE Task Force [2] has already encouraged the screening of atherosclerosis risk factors in younger vulnerable patients potentially having lower total cardiovascular risk based on traditional risk factors.

4.1. Limitations. Whether our results are merely specific to our studied, relatively small population, or may provide general conclusion?

Despite the lower patient number, we got the same results as other studies with more patients; consequently, this smaller sample seems to have the same effect on the surrogate end point. Moreover, our results are in line 
with other studies that proved a similar prevalence of asymptomatic atherosclerosis in the general population $[30,31]$. Consequently, we can assume that using the $8.3 \mathrm{~m} / \mathrm{s}$ cutoff value of PWVao to reveal ACA may be valid for the general population as well, but this presumption needs to be validated.

Another limitation of our study is the fact that it is crosssectional, and no follow-up examination was performed. Nevertheless, asymptomatic carotid atherosclerosis, used as a surrogate end point in our study, has been already proven as a prognostic marker of both cardiovascular morbidity and mortality.

\section{Conclusion}

In conclusion, the study showed an independent association between PWVao, measured by a single upper arm cuff oscillometric method, and ACA in apparently healthy, middle-aged, normotensive population. The simplicity, user independency, and swiftness of the oscillometric method to measure PWVao may contribute to improve cardiovascular risk assessment even in relatively young, middle-aged, apparently healthy population. The solution may provide a future opportunity to implement the screening of this younger population for asymptomatic atherosclerosis potentially leading to the early identification of asymptomatic atherosclerosis and treatment to prevent the progression of the disease.

\section{Data Availability}

The database we have built to prepare this manuscript was created based on the Hungarian/European Union law which was legally binding before 2018. The database contains the measurement per persons with name, date of birth, sex, and measurement values. As currently last year (2018) the GDPR (General Data Protection Regulation, https://ec.europa.eu/ commission/priorities/justice-and-fundamental-rights/ dataprotection/2018-reform-eu-data-protection-rules_en) was introduced in Hungary and in the European Union, we should have from each person who was involved in this study a written contest which complies to the GDPR to share publicly. We are currently working on it, but we can provide it to be available only after we will get from each person the written contest.

\section{Conflicts of Interest}

Miklós Illyés is a patent owner of the Arteriograph method and has shares in TensioMed Ltd., a company that manufactures the Arteriograph device for measuring arterial stiffness. The other authors declare no conflicts of interest.

\section{Authors' Contributions}

The work presented here was carried out in collaboration between all authors. All authors have contributed to, seen, and approved the manuscript.

\section{Acknowledgments}

The authors are grateful to the participants and their families who gave their time to the study. The authors are very grateful to Timo H. Lasola for English corrections. Andras Bikov is supported by the NIHR Manchester BRC.

\section{References}

[1] S. Holewijn, M. den Heijer, A. F. Stalenhoef, and J. de Graaf, "Non-invasive measurements of atherosclerosis (NIMA): current evidence and future perspectives," The Netherlands Journal of Medicine, vol. 68, no. 12, pp. 388-399, 2010.

[2] M. Naghavi, E. Falk, H. S. Hecht et al., "From vulnerable plaque to vulnerable patient-part III: executive summary of the screening for heart attack prevention and education (SHAPE) task force report," The American Journal of Cardiology, vol. 98, no. 2, pp. 2-15, 2006.

[3] A. Simon, G. Chironi, and J. Levenson, "Performance of subclinical arterial disease detection as a screening test for coronary heart disease," Hypertension, vol. 48, no. 3, pp. 392-396, 2006.

[4] J. P. Strong, G. T. Malcom, C. A. McMahan et al., "Prevalence and extent of atherosclerosis in adolescents and young adults," JAMA, vol. 281, no. 8, pp. 727-735, 1999.

[5] J. H. Stein, C. E. Korcarz, R. T. Hurst et al., "Use of carotid ultrasound to identify subclinical vascular disease and evaluate cardiovascular disease risk: a consensus statement from the American Society of Echocardiography carotid intimamedia thickness task force. Endorsed by the society for vascular medicine," Journal of the American Society of Echocardiography, vol. 21, no. 2, pp. 93-111, 2008.

[6] National Cholesterol Education Program, "Expert panel on detection E, treatment of high blood cholesterol in A. Third report of the national cholesterol education program (NCEP) expert panel on detection, evaluation, and treatment of high blood cholesterol in adults (adult treatment panel III) final report," Circulation, vol. 106, no. 25, pp. 3143-3421, 2002.

[7] M. F. Piepoli, A. W. Hoes, S. Agewall et al., "2016 European guidelines on cardiovascular disease prevention in clinical practice: the sixth joint task force of the european society of cardiology and other societies on cardiovascular disease prevention in clinical practice (constituted by representatives of 10 societies and by invited experts)Developed with the special contribution of the european association for cardiovascular prevention \& rehabilitation (EACPR)," European Heart Journal, vol. 37, no. 29, pp. 2315-2381, 2016.

[8] Y. Ben-Shlomo, M. Spears, C. Boustred et al., "Aortic pulse wave velocity improves cardiovascular event prediction: an individual participant meta-analysis of prospective observational data from 17,635 subjects," Journal of the American College of Cardiology, vol. 63, no. 7, pp. 636-646, 2014.

[9] C. Vlachopoulos, K. Aznaouridis, and C. Stefanadis, "Prediction of cardiovascular events and all-cause mortality with arterial stiffness: a systematic review and meta-analysis," Journal of the American College of Cardiology, vol. 55, no. 13, pp. 1318-1327, 2010.

[10] I. J. Kullo, L. F. Bielak, S. T. Turner, P. F. Sheedy 2nd, and P. A. Peyser, "Aortic pulse wave velocity is associated with the presence and quantity of coronary artery calcium: a community-based study," Hypertension, vol. 47, no. 2, pp. 174179, 2006. 
[11] N. M. van Popele, D. E. Grobbee, M. L. Bots et al., "Association between arterial stiffness and atherosclerosis: the Rotterdam study," Stroke, vol. 32, no. 2, pp. 454-460, 2001.

[12] M. Selwaness, Q. van den Bouwhuijsen, F. U. Mattace-Raso et al., "Arterial stiffness is associated with carotid intraplaque hemorrhage in the general population: the Rotterdam study," Arteriosclerosis, Thrombosis, and Vascular Biology, vol. 34, no. 4, pp. 927-932, 2014.

[13] M. Zureik, J. M. Bureau, M. Temmar et al., "Echogenic carotid plaques are associated with aortic arterial stiffness in subjects with subclinical carotid atherosclerosis," Hypertension, vol. 41, no. 3, pp. 519-527, 2003.

[14] X. Castellon and V. Bogdanova, "Screening for subclinical atherosclerosis by noninvasive methods in asymptomatic patients with risk factors," Clinical Interventions in Aging, vol. 8, pp. 573-580, 2013.

[15] A. D. Giannoukas, M. Chabok, K. Spanos, and A. Nicolaides, "Screening for asymptomatic carotid plaques with ultrasound," European Journal of Vascular and Endovascular Surgery, vol. 52, no. 3, pp. 309-312, 2016.

[16] P. J. Touboul, M. G. Hennerici, S. Meairs et al., "Mannheim carotid intima-media thickness and plaque consensus (2004-2006-2011). An update on behalf of the advisory board of the $3 \mathrm{rd}$, 4 th and 5 th watching the risk symposia, at the 13 th, 15th and 20th European stroke conferences, Mannheim, Germany, 2004, Brussels, Belgium, 2006, and Hamburg, Germany, 2011," Cerebrovascular Diseases, vol. 34, no. 4, pp. 290-296, 2012.

[17] J. Baulmann, U. Schillings, S. Rickert et al., "A new oscillometric method for assessment of arterial stiffness: comparison with tonometric and piezo-electronic methods," Journal of Hypertension, vol. 26, no. 3, pp. 523-528, 2008.

[18] I. G. Horvath, A. Nemeth, Z. Lenkey et al., "Invasive validation of a new oscillometric device (Arteriograph) for measuring augmentation index, central blood pressure and aortic pulse wave velocity," Journal of Hypertension, vol. 28, no. 10, pp. 2068-2075, 2010.

[19] Z. Nemeth, K. Moczar, and G. Deak, "Evaluation of the tensioday ambulatory blood pressure monitor according to the protocols of the British hypertension society and the association for the advancement of medical instrumentation," Blood Pressure Monitoring, vol. 7, no. 3, pp. 191-197, 2002.

[20] M. J. Roman, T. G. Pickering, J. E. Schwartz, R. Pini, and R. B. Devereux, "Association of carotid atherosclerosis and left ventricular hypertrophy," Journal of the American College of Cardiology, vol. 25, no. 1, pp. 83-90, 1995.

[21] W. F. Enos, R. H. Holmes, and J. Beyer, "Coronary disease among United States soldiers killed in action in Korea; preliminary report," Journal of the American Medical Association, vol. 152, no. 12, pp. 1090-1093, 1953.

[22] T. P. van Staa, M. Gulliford, E. S. Ng, B. Goldacre, and L. Smeeth, "Prediction of cardiovascular risk using Framingham, ASSIGN and QRISK2: how well do they predict individual rather than population risk?," PLoS One, vol. 9, no. 10, Article ID e106455, 2014.

[23] N. J. Wald, J. K. Morris, and S. Rish, "The efficacy of combining several risk factors as a screening test," Journal of Medical Screening, vol. 12, no. 4, pp. 197-201, 2005.

[24] N. J. Wald and M. R. Law, "A strategy to reduce cardiovascular disease by more than 80\%," BMJ, vol. 326, no. 7404, p. $1419,2003$.

[25] J. H. Ware, "The limitations of risk factors as prognostic tools," New England Journal of Medicine, vol. 355, no. 25, pp. 2615-2617, 2006.
[26] M. Task Force, G. Montalescot, U. Sechtem et al., “2013 ESC guidelines on the management of stable coronary artery disease: the task force on the management of stable coronary artery disease of the European society of cardiology," European Heart Journal, vol. 34, no. 38, pp. 2949-3003, 2013.

[27] L. Fernandez-Friera, J. L. Penalvo, A. Fernandez-Ortiz et al., "Prevalence, vascular distribution, and multiterritorial extent of subclinical atherosclerosis in a middle-aged cohort: the PESA (progression of early subclinical atherosclerosis) study," Circulation, vol. 131, no. 24, pp. 2104-2113, 2015.

[28] B. Williams, G. Mancia, W. Spiering et al., "2018 ESC/ESH guidelines for the management of arterial hypertension: the task force for the management of arterial hypertension of the European society of cardiology and the european society of hypertension: the task force for the management of arterial hypertension of the European society of cardiology and the European society of hypertension," Journal of Hypertension, vol. 36, no. 10, pp. 1953-2041, 2018.

[29] L. M. Van Bortel, S. Laurent, P. Boutouyrie et al., "Expert consensus document on the measurement of aortic stiffness in daily practice using carotid-femoral pulse wave velocity," Journal of Hypertension, vol. 30, no. 3, pp. 445-448, 2012.

[30] M. F. Eleid, S. J. Lester, T. L. Wiedenbeck et al., "Carotid ultrasound identifies high risk subclinical atherosclerosis in adults with low framingham risk scores," Journal of the American Society of Echocardiograph, vol. 23, no. 8, pp. 802-808, 2010.

[31] V. Nambi, L. Chambless, A. R. Folsom et al., "Carotid intimamedia thickness and presence or absence of plaque improves prediction of coronary heart disease risk: the ARIC (Atherosclerosis risk in communities) study," Journal of the American College of Cardiology, vol. 55, no. 15, pp. 1600-1607, 2010. 


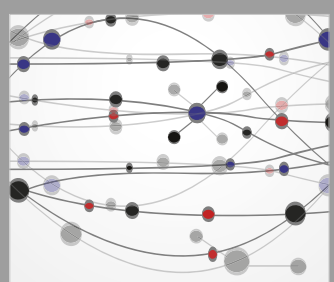

The Scientific World Journal
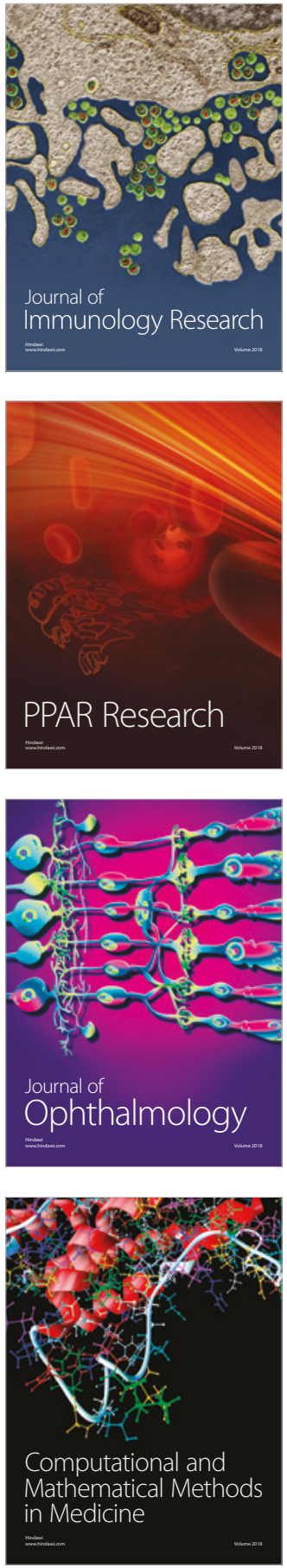

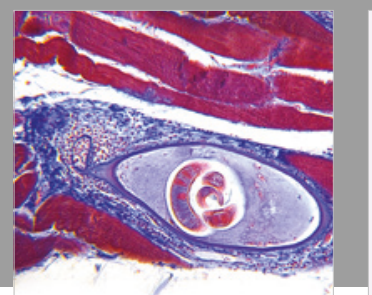

Gastroenterology Research and Practice

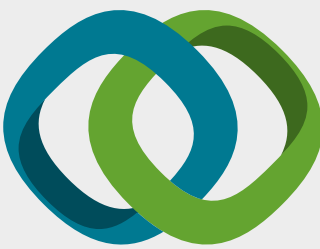

\section{Hindawi}

Submit your manuscripts at

www.hindawi.com
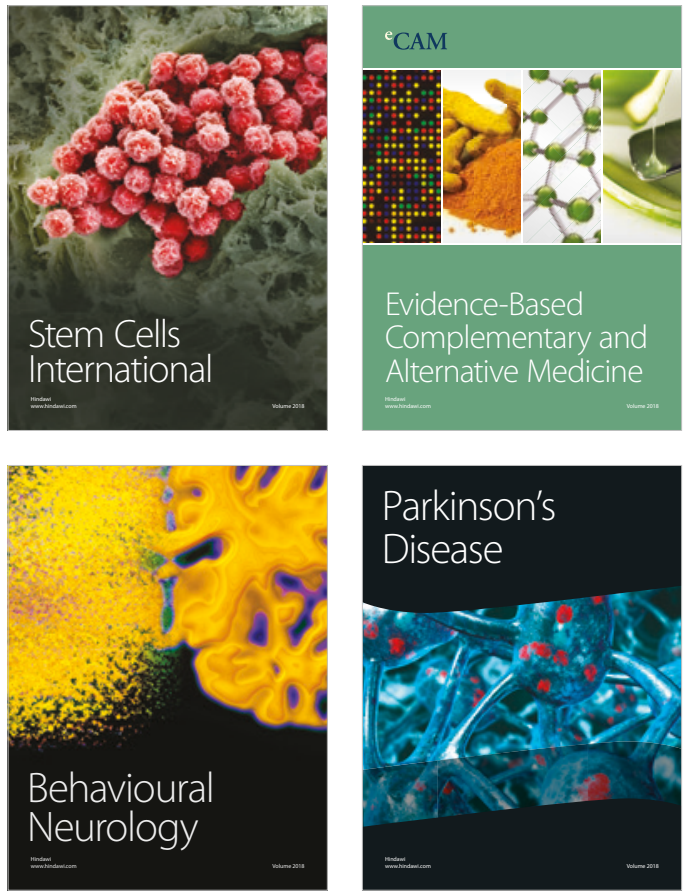

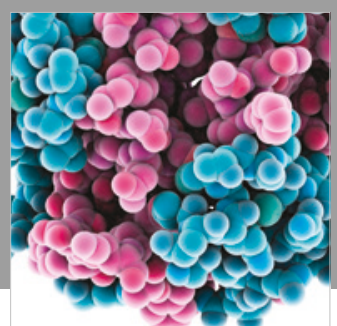

ournal of

Diabetes Research

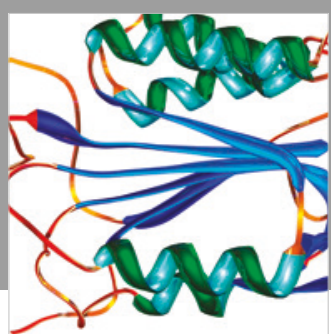

Disease Markers
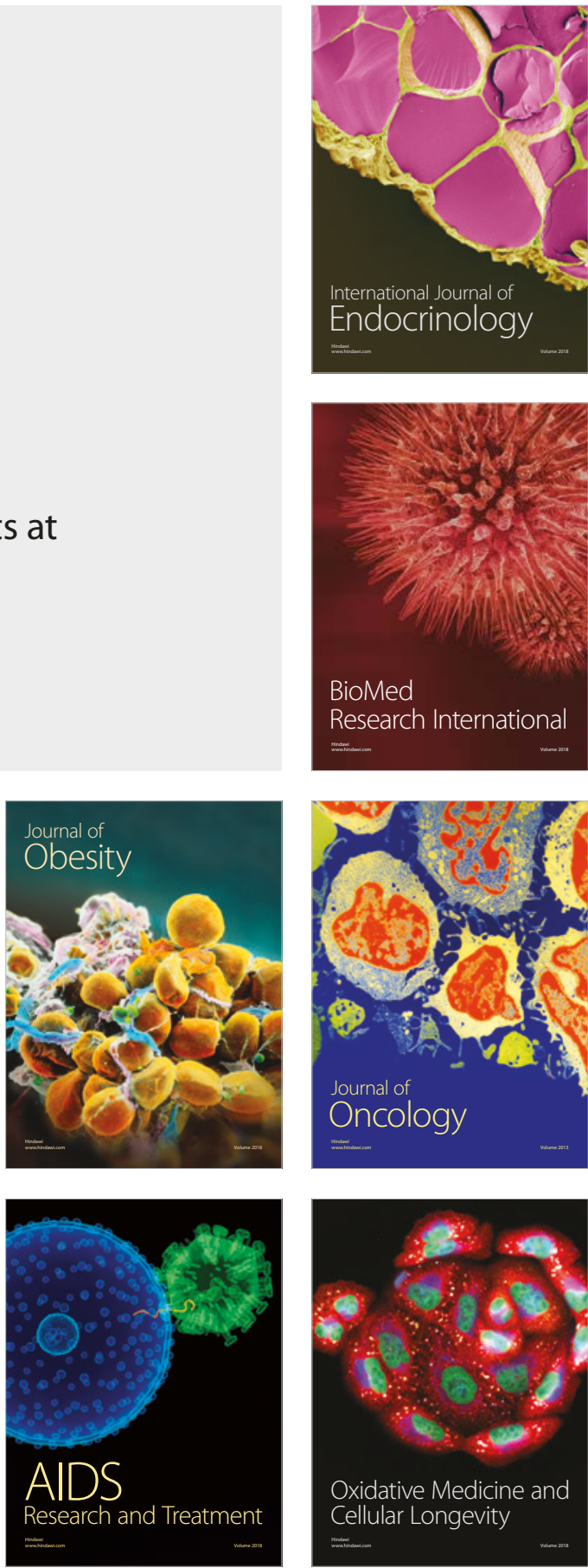